\title{
Spectral Library Creation of Garnet in Kadavur Basin, Karur District, Tamil Nadu, India - A Lab-Based Spectral Library Creation
}

\author{
Varsha Prem, B.Gurugnanam, Sulochana Shekhar and Sorna Chandra Devadass C
}

\begin{abstract}
The significance of the study is to create a spectral library for the mineral Garnet. The spectra for Garnet created in the darkroom environment for the study. The laboratory spectra created matched with the USGS spectral library and made confirmation for the spectra. For the spectral resampling and spectral matching, ASTER data used as the reflectance file. The wavelength of the laboratory spectra is between 0.556 to 2.4 micrometres. The highest reflectance spectral curve of the laboratory spectra shows 1.00 reflectance value and the wavelength is $0.807 \mu m$. The USGS spectra also indicate the same value and wavelength. The absorption value changes in lab spectra at 0.57 reflectance value at the wavelength of $1.65 \mu \mathrm{m}$. The USGS spectra display 0.506 absorption value at the same wavelength of the laboratory spectra. The USGS spectra of the Garnet shows that the Garnet collected from the study area is Spessartine garnet. The laboratory spectral library thus created can be used for the mineral identification and also the spectral library thus created can use for further studies.
\end{abstract}

Keywords: Garnet, USGS Spectral Library, Laboratory spectral library, spectral library, spectral resampling.

\section{INTRODUCTION}

Reflectance spectroscopy is a promptly emerging science that can use to develop relevant data about minerals [1]. Reflectance data collection means, it is the ground-based measurement of the reflectance or emittance of surface materials for defining their spectral response patterns. It can do in a laboratory or the field [2]. A spectroradiometer used for this purpose. The energy is coming from an object as a role of wavelength measured by using this device. It is used mainly for the preparation of spectral reflectance curves for various objects [2].

For the present study, the spectra of the garnet have taken in the laboratory. It took in a dark room environment by using a spectroradiometer called ASD Fieldspec 4 instrument.

For many applications such as the measurement of reflectance, transmittance or irradiance of an object the Fieldspec 4 instrument is used as spectroradiometer. RS3 Software used for saving the collected spectra of the material.

Revised Manuscript Received on October 15, 2019.

Varsha Prem, Centre for Applied Geology, The Gandhigram Rural Institute - Deemed to be University, Dindigul, Tamil Nadu, India.(Email: varsha.prem34@gmail.com)

Gurugnanam B, Centre for Applied Geology, The Gandhigram Rura Institute - Deemed to be University, Dindigul, Tamil Nadu, India.(Email: gurugis4u@gmail.com)

Sulochana Shekhar, Department of Geography, Central University of Tamil Nadu, Thiruvaru, India, (Email: sulochana@cutn.ac.in)

Sorna Chandra Devadass C, Department of Civil Engineering, Samskruti College of Engineering and Technology, Ghatkesar, Hyderabad, India. (Email: rajkiran.smskcivil@gmail.com)
Advanced Spaceborne Thermal Emission and Reflection Radiometer (ASTER) images can reveal successfully the mineralogical variations and alterations induced by both physical and chemical factors which represent the opening of the mineral exploration that could make a direct appeal of growth in economic conditions [3]. Atmospheric correction (FLAASH) applied to the ASTER data. The ASTER data measures reflected solar radiation in VNIR, SWIR and TIR regions. It has 14 bands. The VNIR region has three bands and range is between $0.52-0.86 \mu \mathrm{m}$. The SWIR region contains six bands from $1.6 \mu \mathrm{m}$ to $2.43 \mu \mathrm{m}$ wavelength. The last five bands come in TIR region which shows the range between $8.12 \mu \mathrm{m}$ to $11.65 \mu \mathrm{m}$. In this study the ASTER data is used as a platform for correlating the USGS spectra and the laboratory spectra [4], [5], [6].

Garnet comes under Neso silicates. It crystallises in Isometric system which has common forms like the dodecahedron and trapezohedron or sometimes with hexoctahedron. It shows different colours like red, brown, black, green and apple green - this colour change based on chemical composition. The streak is white. It is transparent to subtranslucent often in irregular embedded grains. Also massive, granular, coarse or fine and sometimes friable, lamellar, thick and bent. Fracture sub-conchoidal to uneven. Brittle, sometimes friable when granular massive. Lustre vitreous to resinous [7]. For the study, the sample collected from the area called Sevapure, which located at $78^{\circ} 12^{\prime} 15.26^{\prime \prime} \mathrm{E}, 10^{\circ} 35^{\prime} 52.644^{\prime} \mathrm{N}$. Here, the mineral was found associated with Quartz.

\section{STUDY AREA}

From Sevapure area of Kadavur basin, the sample collected (fig. 1). The survey of India Toposheet 58J/2 and $58 \mathrm{~J} / 6$ covers the Kadavur basin. Most of the Kadavur basin covered by reserve forest and it is rich with minerals. The Geological Survey of India's Geological Resource map gives an idea about the lithology of the Kadavur basin. Based on the map the study area is composed of Calcgranulite and limestone, Quartzite, Pink migmatite, Hornblende -biotite-gneiss, Kadavur Anorthosite and Ultramafic. The Sevapure area composed of Ultramafic. [8], [9], [10], [11]. 


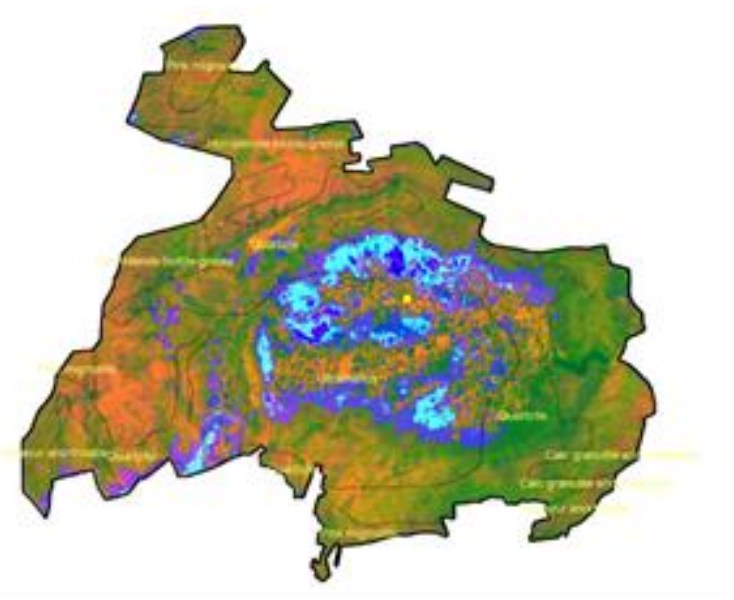

Fig. 1 Overlay of Geology Map of the Kadavur Basin in PCA derived FCC band combination Band 8, Band 4, and Band 1

\section{METHODOLOGY}

From the Sevapure area, the sample collected. By the megascopic identification of the sample, it identified as Garnet. By using the ASD Fieldspec 4 spectroradiometer, the laboratory spectra of the sample have taken. Spectral reflectance, spectral absorbance, spectral transmittance, spectral radiance and spectral irradiance can measure by using this instrument [12]. The spectra taken by the instrument saved as ASD file format and this format is work with ENVI software. The spectra of the sample took in a dark room for reducing the noise while taking the spectra. Thus taken spectra is used as Garnet laboratory spectra.

The Atmospheric correction of the ASTER data did by using the FLAASH tool present in the ENVI software. This atmospherically corrected data used as a reflectance file for the spectra identification. For the confirmation of the mineral spectra, the laboratory spectra have to match with the USGS spectra. For the better result, before doing this, both the laboratory spectra and USGS spectra has to be resampled. Finally, it completed by using the spectral resampling tool present in the ENVI software. This resampling technique is used to remove the spectral intervals between the laboratory spectra and USGS spectra.

For the comparison of both spectra, a reflectance file needed and here, ASTER data used as the reflectance file. After loading the true colour of the ASTER data, from the spectral library viewer, the laboratory spectra have been selected and can match with the USGS spectral library.

The methodology flow chart of the spectral library creation shows below.

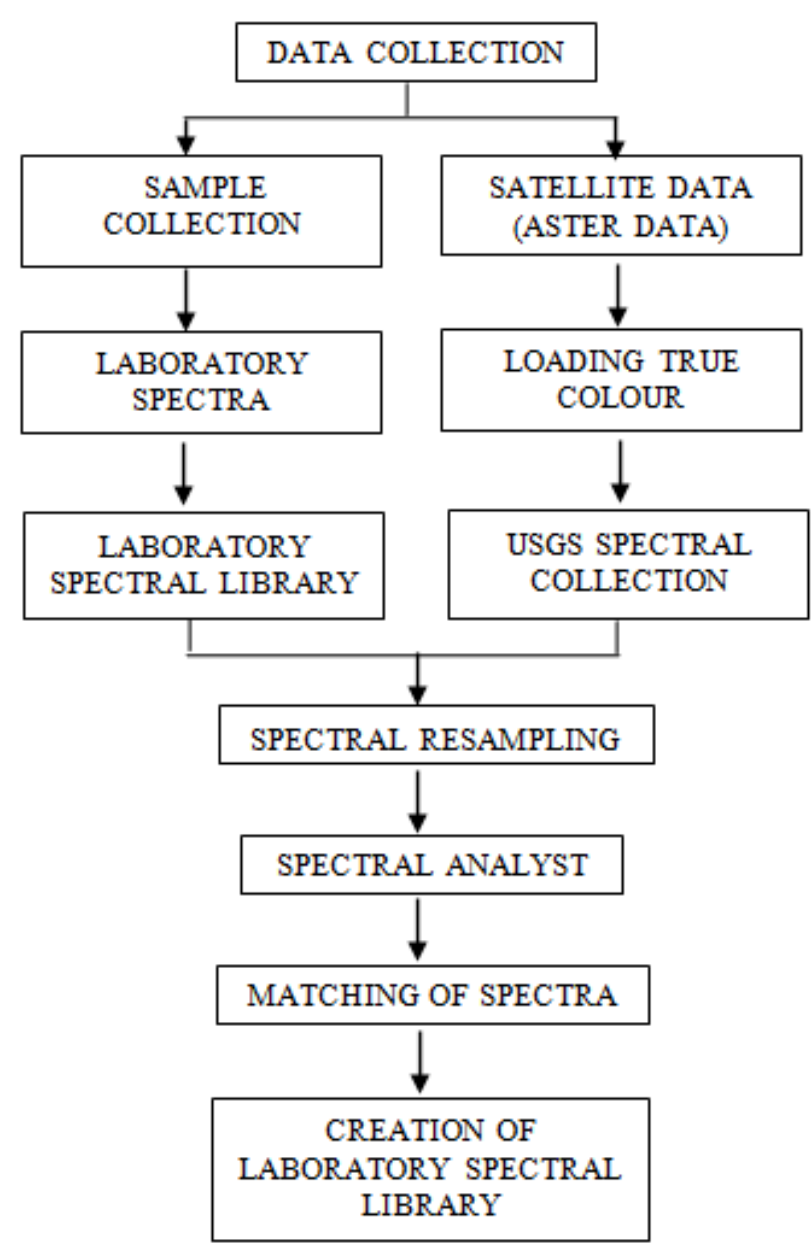

Fig. 2 Methodology flow chart

\section{RESULT AND DISCUSSIONS}

The physical properties of the mineral are used for the megascopic identification (Fig. 3) of mineral. The physical properties like its red colour, dodecahedral form, white streak, vitreous lustre and translucent to opaque.

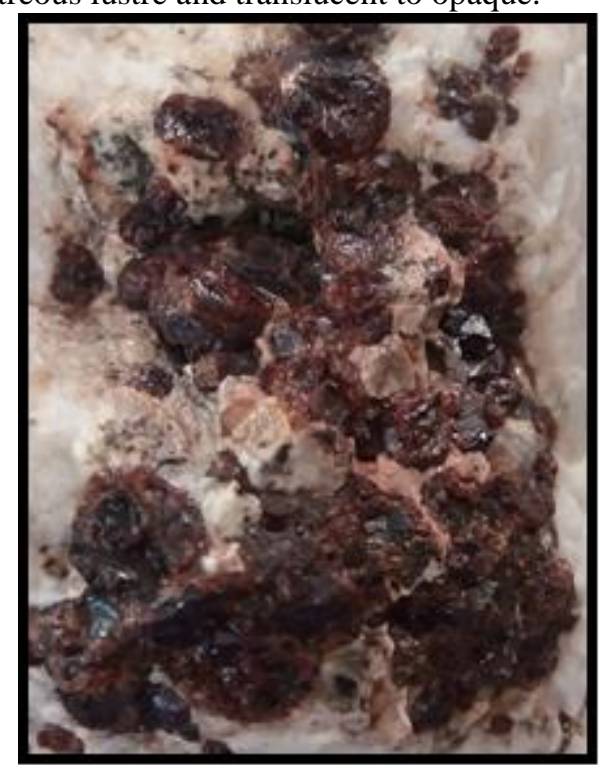

Fig: 3 Garnet associated with quartz 
The laboratory spectra after resampling, (Fig.4 \& 5) it has matched with USGS spectra. The score value of the spectral analyst result of Spectral Angle Mapper (SAM), Spectral Feature Fitting (SFF), and Binary Encoding (BE) is 0.776, 0.653 , and 1.00 , respectively. The total score value is 2.429 . The laboratory spectra identified as Spessartine mineral which comes under Garnet family while matching with the USGS spectral library.

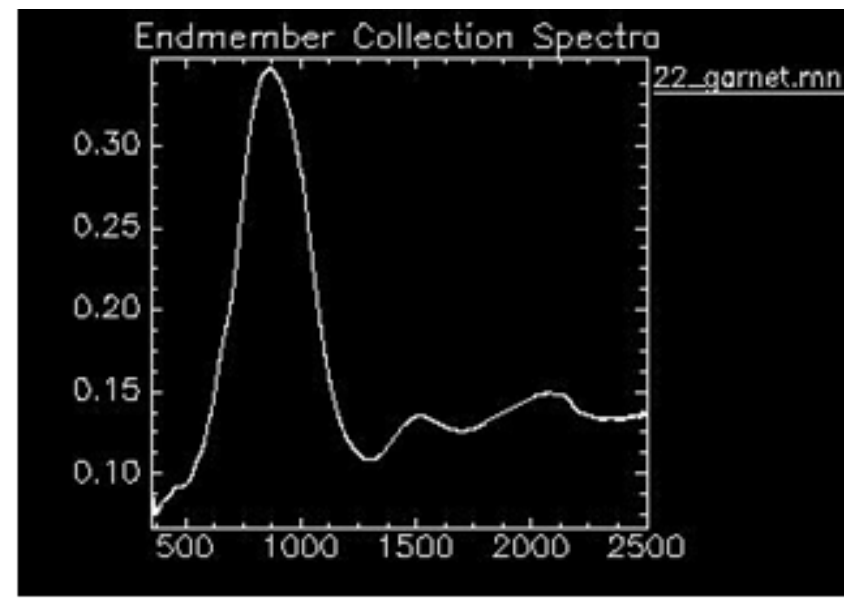

Fig. 4 Laboratory spectra before resampling

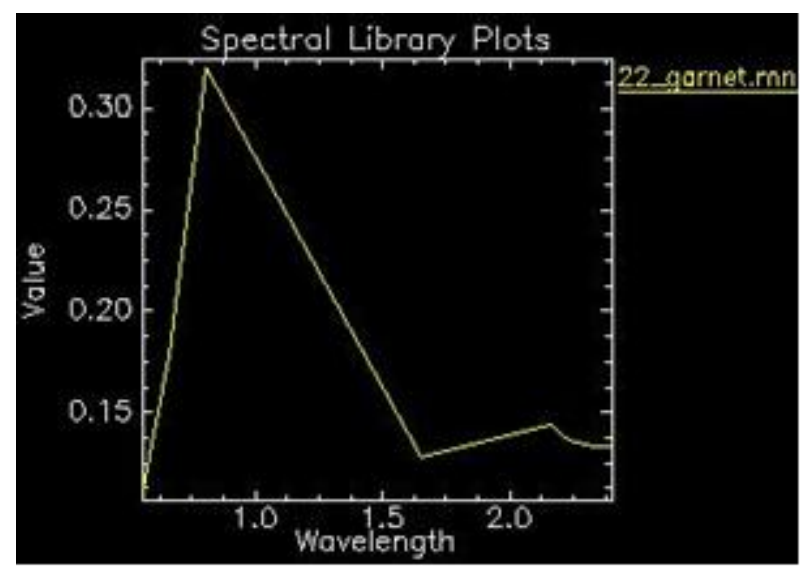

Fig. 5 Laboratory spectra after resampling

In Fig. 6, the red colour shows the laboratory spectra and the white colour shows the USGS spectra. The USGS spectra and the laboratory spectra show match with the Spessartine garnet, in USGS spectral library the mineral is named as spessar1.spc Spessartine NMNH14143 and in laboratory spectra it is named as 22_garnet. In laboratory spectra, the spectra have formed between 0.556 to 2.4 micrometres. The highest reflectance spectral curve of the laboratory spectra has 1.00 reflectance value at $0.807 \mu \mathrm{m}$ wavelength. The same reflectance value and wavelength have shown by the USGS spectral library. The absorption value of laboratory spectra and the USGS spectral library is 0.57 and 0.506 respectively, but the wavelength of $1.65 \mu \mathrm{m}$ is same for both.

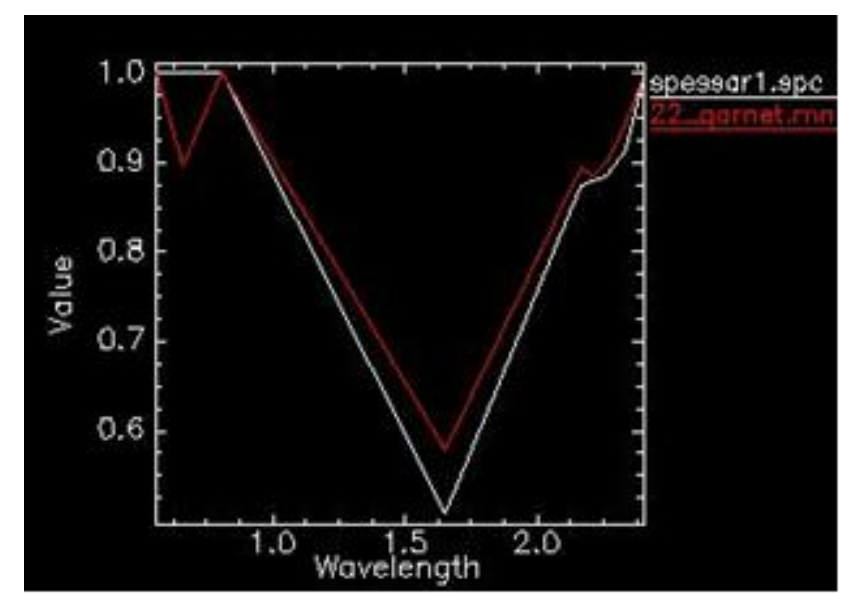

Fig. 6 Laboratory spectra and USGS Spectra

\section{CONCLUSION}

The megascopic identification of Garnet made by using its physical properties. By using the spectral library it can be identified that the sample collected is Spessartine garnet. The spectral library created can be used to find out the minerals and also for future uses.

\section{ACKNOWLEDGMENT}

The authors are thankful to The Gandhigram Rural Institute - deemed to be University authorities for providing facilities for the research work.

\section{REFERENCES}

1. Kumara Ganesh, U \& Thamarai Kannan, S. 2017, "Creation of hyperspectral library and lithological discrimination of granite rocks using SVCHR - 1024: lab-based approach", Journal of Hyperspectral Remote Sensing, vol.7, no.3 (2017), pp, 168-177.

2. Aarthy, R.S., and Sanjeevi, S. 2008, "Relating VNIR spectra and mineralogy of anorthosites", 29th Asian Conference on Remote Sensing 2008, ACRS 2008. 2. 8181-823.

3. Rajasimman Balasubramanian, U.A.B., Saravanavel, J., and Gunasekaran, S. 2013, "Ore mineral discrimination using hyperspectral remote sensing - a field-based spectral analysis", Arabian Journal of Geoscience, vol.6, pp.4709-4716.

4. Enton Bedini. 2018, "Application of Advanced Spaceborne Thermal Emission and reflectance Radiometer (ASTER) multispectral imagery to mineral and lithological mapping in Southern West Greenland", Journal of Remote Sensing, vol.8, no.2, pp. 47-59.

5. Bhadra, B.K., Suparn Pathak, Karunakar, G. \& Sharma J.R. 2013, "ASTER Data Analysis for Mineral Potential Mapping Around Sawar-Malpura Area, Central Rajasthan", Journal of Indian Society of Remote Sensing, vol. 41, no.2, pp. 391-404.

6. Feizollah Masoumi, Taymour Eslamkish, Mehdi Honarmand \& Ali Akbar Abkar. 2017, "Utilization of ASTER Data and Spectral Analysis to Discriminate Hydrothermally Altered Areas over Rabor, South of Kerman, Iran", Journal of Indian Society of Remote Sensing, vol. 45, no. 6, pp. 1039-1055. 
7. William E. Ford. 2002, "Dana's Textbook of Mineralogy" Fourth Edition, CBS Publishers, ISBN: 81-239-0809-1.

8. Subramanian, A.P., 1956, "Petrology of the Anorthosite Gabbro mass at Kadavur, Madras, India", Geol.mag, 93, pp. 287-30.

9. Vinoth Kumar, M., Kumar, R.S., Rajaprian, K. \& Singh Kuldeep. 2013, "Petrography and Major Geochemical Studies of Anorthosite, Kadavur and Adjoining Area, Tamilnadu, India", International Research Journal of Earth Science, vol. 1, no. 5, pp. 15-22.

10. (Vinoth Kumar, M., Kumar, R.S., Rajaprian, K. \& Kuldeep Singh. 2014, "Mineralogical studies of Plagioclase Feldspar in Kadavur Anorthosite Complex, Tamilnadu", International Journal of Advanced Geoscience, vol.2, no. 2, pp. 31-37.

11. Vinod Kumar, M., Kumar, R.S., Rajaprian, K. \& Kuldeep Singh. 2013, "Geological and Petrological Studies of Pegmatites Rocks of in and around Kadavur Area, Karur District, Tamilnadu", vol. 2, no. 3, pp. 182191.

12. Ravi Gupta, P. 2002, "Remote Sensing Geology" Second Edition, Springer, ISBN: 3-540-43185-3.

\section{AUTHORS PROFILE}

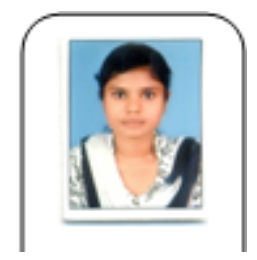

Varsha prem, is a Ph.D., Scholar in Centre for Applied Geology, The Gandhigram Rural Institute - Deemed University. She did B.Sc., in Geology and M.Sc., in Applied Geology and Geomatics. Right now, she is doing Ph.D., in Geospatial Technology-based Mineral studies.

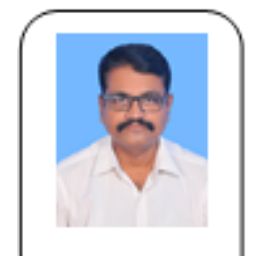

Dr.B.Gurugnanam, is a Professor of Geology in Center for Applied Geology, The Gandhigram Rural Institute - Deemed to be University. He has graduated in B.Sc., Geology and M.Sc., Applied Geology from Bharathidasan University. He did M.Phil, in Geology from University of Madras and M.Tech, in remote sensing from Bharathidasan University. He did Ph.D., in Geospatial Technology application in water resources and specialised in Georesources, Disaster and Climate Change. He has 24 years of experience.

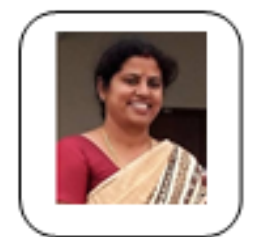

Dr.Sulochana Shekhar, is a Professor and Dean, School of Earth Sciences Head, Department of Geography, School of Earth Sciences, Coordinator, Internal Quality Assurance Centre, Coordinator, STRIDE, UGC Scheme, Central University of Tamil Nadu, Thiruvarur, Tamil Nadu, India. She specialised in Remote Sensing and GIS techniques.

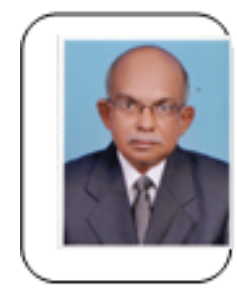

Dr.C.Sorna Chandra Devadass is a Professor in the Department of Civil Engineering, Samskruti College of Engineering and Technology, Jawaharlal Nehru Technical University. He did B.E in Civil Engineering from PSG College of Technology, Coimbatore, and M.E in Civil Engineering from Government College of Technology, Coimbatore. He has completed Ph.D.in Civil Engineering from Anna University, Chennai. He has 34 years of professional teaching and research experience in civil Engineering. $\mathrm{He}$ is interested in GIS, Environmental Engineering. 